\title{
Using an observer rating method to assess the effects of rotational stocking method on beef cattle temperament over time
}

\author{
Karen Camille Rocha Góis ${ }^{1,2}$, Maria Camila Ceballos ${ }^{1,2}$, Aline Cristina Sant'Anna ${ }^{1,3}$, Mateus José \\ Rodrigues Paranhos da Costa ${ }^{1,4}$
}

\footnotetext{
${ }^{1}$ Universidade Estadual Paulista, Grupo de Estudos e Pesquisas em Etologia e Ecologia Animal, Jaboticabal, SP, Brazil.

2 Universidade Estadual Paulista, Faculdade de Ciências Agrárias e Veterinárias, Programa de Pós-graduação em Zootecnia, Jaboticabal, SP, Brazil.

${ }^{3}$ Universidade Federal de Juiz de Fora, Instituto de Ciências Biológicas, Departamento de Zoologia, Juiz de Fora, MG, Brazil.

${ }^{4}$ Universidade Estadual Paulista, Faculdade de Ciências Agrárias e Veterinárias, Departamento de Zootecnia, Jaboticabal, SP, Brazil.
}

\begin{abstract}
The objectives of this study were to propose behavioral-based definitions for the adjectives used in an observer rating method, and to use this approach to characterize temperament over time in cattle kept under rotational stocking method. We also analyzed the feasibility of the rating method under commercial cattle farming conditions. We evaluated the temperament evolution of 1,979 pure and crossbred Nellore young bulls over time on three commercial farms located in Northeastern Pará State, Brazil. All animals were kept under a rotational stocking method. The observer rating method included 14 behaviorally predefined adjectives for which we defined the minimum and maximum scores. The first factor was considered a qualitative temperament index (QTI) ranging from 'relaxed'/‘calm'/'comfortable' to 'fearful'/'agitated'. According to the QTI, cattle temperament improved over time. For Farms A and B, QTI decreased over evaluations, and for Farm C, QTI did not differ from the first to the second evaluations, but decreased from the second assessment onwards. The observer rating method consisting of behaviorally pre-defined adjectives is an adequate indicator of cattle temperament that may be feasible under farm conditions. The method captures different aspects of cattle temperament and distinguishes between slight variations in cattle body language that successfully reveal temperament changes over time.
\end{abstract}

Key Words: behavior, qualitative behavior assessment, rotational stocking method

\section{Introduction}

Observer rating methods have long been used in research on human (Allport and Odbert, 1936; Deary, 1996) as well as animal behavior, to assess individual differences and temperament (or personality) of captive wild animals such as rhesus monkeys (Stevenson-Hinde and Zunz, 1978), gorillas (Gold and Maple, 1994; Kuhar et al., 2006), cheetahs (Wielebnowski, 1999), rhinoceros (Carlstead et al., 1999), tufted capuchin (Byrne and Suomi, 2002), chimpanzees (Martin, 2005; Weiss et al., 2007), and African elephants (Grand et al., 2012). Furthermore, a similar qualitative approach - Qualitative Behavior Assessment (QBA; Wemelsfelder et al., 2000) - was developed to assess welfare in farm animals and has been shown to be a valid and reliable method in swine (Wemelsfelder et al., 2000), dairy cattle (Rousing and Wemelsfelder, 2006), beef cattle (Stockman et al., 2012), dairy buffalo (Napolitano

Received February 1, 2016 and accepted July 14, 2016.

Corresponding author: mpcosta@fcav.unesp.br

http://dx.doi.org/10.1590/S1806-92902016000900001

Copyright (C) 2016 Sociedade Brasileira de Zootecnia. This is an Open Access article distributed under the terms of the Creative Commons Attribution License (http://creativecommons.org/licenses/by/4.0/), which permits unrestricted use, distribution, and reproduction in any medium, provided the original work is properly cited. et al., 2012), sheep (Phythian et al., 2013), and donkeys (Minero et al., 2015). Despite the vast literature employing rating methods to assess temperament of captive wild animals, these methods have rarely been used to assess the temperament of farm species.

To our knowledge, one of the first studies using an observer rating method to assess cattle temperament was conducted by Sant'Anna and Paranhos da Costa (2013). In that study, the authors compared QBA with four other methods traditionally used to assess cattle temperament: flight speed test, visual scores of movement in the cattle crush, crush score, and a temperament score in a corral pen. They concluded that QBA was more efficient at detecting slight variations in cattle behavior during handling in the corral, and was thus better at identifying a wider range of behavioral profiles and distinguishing animals with desirable temperaments.

Despite those positive results, there are still some criticisms regarding the subjectivity of the methodology, which can result from observer bias (Bokkers et al., 2012; Tuyttens et al., 2014). One way to overcome this limitation would be to use a rating method with behaviorally defined adjectives (Martin and Bateson, 2007). The aims of this study were: to test an observer rating method using adjectives with behaviorally based definitions to assess 
temperament over time in cattle kept under rotational stocking method, and to assess the feasibility of the rating method under commercial cattle farming conditions.

\section{Material and Methods}

All procedures performed in this study were approved by the Ethics Committee in Animal Use (Certified n. 020939/13 and 020938/13) of the Faculty of Agricultural and Veterinary Sciences of São Paulo State University (Jaboticabal-SP, Brazil).

We used an observer rating method to evaluate the evolution of temperament in 1,979 Nellore (pure and crossed) young bulls (averaging $21 \pm 3$ months old) over time, on three commercial farms located in Northeastern Pará State, Brazil, herein referred to as Farms A, B, and C. All stockpersons were previously trained in good practices of handling in order to reduce cattle stress levels during handling in the corral.

All animals were kept under a grazing system and were subjected to a rotational stocking method (RSM), which is defined as 'a method that utilizes recurring periods of grazing and rest among three or more paddocks in a grazing management unit throughout the time when grazing is allowed' (Allen et al., 2011). The animals were rotated in modules of eight paddocks each and were moved from one paddock to another about every four days (period of stay), with approximately 28 days of rest (resting period), depending on forage height. The stocking density was about three animal units (AU) per hectare. The animals were subjected to monthly weighing for stocking density adjustment. Vaccination and deworming occurred every six months, concurrently with weighing. We used an observer rating method to evaluate the evolution of temperament in 1,979 Nellore (pure and crossed) young bulls (averaging $21 \pm 3$ months old) over time, on three commercial farms located in Northeastern Pará State, Brazil, herein referred to as Farms A, B, and C (Table 1).

The animals entered the RSM in early December 2012 and the temperament assessments were conducted from the end of January to June 2013 (around 40 days after animals entered the RMS) and were repeated every 35 days, on average, when the animals were driven to the corral for weighing. Data from two temperament evaluations (EV) at Farm A, three at Farm B, and four at Farm C were used in this study.

The observer rating method was used as a temperament indicator and was applied with the animals kept in a corral pen, just after they exited the squeeze crush. Behavioral observations were designed to interfere as little as possible with the handling routine. The handling speed was around 120 heads weighed per hour (30 s/animal); thus, the observer had a short time interval to observe each animal individually (for around $5 \mathrm{~s}$ ) and then describe its body language using a list of adjectives. The list was adapted from Sant'Anna and Paranhos da Costa (2013), from which we eliminated two adjectives ('happy' and 'distressed') and introduced four new ones ('sociable', 'indifferent', 'comfortable', and 'aggressive'), leaving a total of 14 adjectives ('active', 'relaxed', 'fearful', 'agitated', 'calm', 'attentive', 'positively occupied', 'curious', 'irritable', 'apathetic', 'comfortable', 'aggressive', 'sociable', and 'indifferent'). The numbers of adjectives expressing positive and negative aspects of temperament were balanced. Each adjective was behaviorally predefined, as recommended by Lerman et al. (2010), to reduce observer bias (Table 2). They were quantified along a $125 \mathrm{~mm}$ visual analog scale, which indicates the intensity of each behavioral expression. We then measured the distances (in $\mathrm{mm}$ ) from the left margin (minimum) up to the mark of the observer for each adjective, thus defining the numeric scores.

Rating was conducted by only one trained person, who performed a test-retest reliability evaluation using video clips from a subsample of 100 cattle. The observer scored two video sessions within a 10-day interval. Pearson's correlation coefficients were used to evaluate the intraobserver reliability for each adjective, which yielded high values $(r \geq 0.70)$ for six of them ('calm', 'comfortable', 'fearful', 'curious', 'sociable', and 'aggressive'), moderate $(0.50 \geq \mathrm{r}<0.70)$ for three ('active', 'relaxed', and 'agitated'), and low $(\mathrm{r}<0.50)$ for one adjective ('attentive'). The remaining four adjectives ('positively occupied', 'irritable', 'apathetic', and 'indifferent') had low variation (many animals were scored ' 0 ') and it was therefore not possible to calculate their correlation coefficients.

A multivariate factor analysis was applied to the adjectives using Statistica software (Statsoft, version 7). A

Table 1 - Characteristics of the groups of cattle on all farms

\begin{tabular}{lcccl}
\hline Farm & Group & $\mathrm{N}$ & Age & \multicolumn{1}{c}{ Breed } \\
\hline A & 1 & 565 & $20 \pm 1.4$ & Nellore \\
B & 2 & 220 & $17 \pm 4.2$ & Nellore \\
& 3 & 102 & $26 \pm 6.0$ & Nellore \\
& 4 & 183 & $32 \pm 2.7$ & Nellore \\
& 5 & 253 & $20 \pm 3.0$ & Angus $\times$ Nellore $(\mathrm{N}=229)$, Charolais $\times$ \\
& & & & Nellore (N=24) \\
C & 6 & 180 & $30 \pm 1.6$ & Nellore \\
& 7 & 149 & $11 \pm 1.1$ & Angus $\times$ Nellore \\
& 8 & 198 & $20 \pm 3.7$ & Nellore $(\mathrm{N}=175)$, Crossbred $(\mathrm{N}=23)$ \\
& 9 & 129 & $17 \pm 2.8$ & Charolais $\times$ Nellore $(\mathrm{N}=82)$, \\
& & & & Crossbred (N = 47) \\
\hline
\end{tabular}

Quantity of assessed group per farm (Group), number of animals per lot (N), average age in months (Age), and the cattle breeds (Breed). 
factor analysis is characterized as a multivariate exploratory technique that allows one to define the relation among a set of variables (adjectives) to be explained in terms of a limited number of new variables (the factors), the latter being assumed to be responsible for the covariation among the observed variables.

We used the principal components method to extract factors, using the correlation matrix among variables
(Jeffers, 1978). The first factor extracted from that matrix is the linear combination of the original variables, which accounts for as much of the variation contained in the samples as possible. The second factor is the second linear function of the original variables, which accounts for most of the remaining variability, and so on. Factors are independent of one another, have no units, and are standardized variables (normal distribution, mean $=0$,

Table 2 - Definitions of cattle behavioral categories used in the observer rating assessment, describing the behavioral expressions that characterize the minimum and maximum scores for each adjective

\begin{tabular}{lll}
\hline Adjective & \multicolumn{1}{c}{ Definition } & \multicolumn{1}{c}{ Minimum } \\
\hline Active & $\begin{array}{l}\text { Related to motor activities, considering the } \\
\text { time spent in and the speed of displacement. }\end{array}$ & $\begin{array}{l}\text { The animal stops after exiting the crush, } \\
\text { or moves very little and stops. }\end{array}$
\end{tabular}

Relaxed Related to the degree of muscle tension and frequencies of ears, tail, and head movements.

Animal shows strong muscle tension and constant ears, tail, and head movements.

Fearful Related to escape or avoidance behavior and occurrence of muscle tremor.

Agitated Related to the frequency and intensity of movements of ears, tail, head, and limbs, as well as the presence of audible breathing.

Calm Related to the absence of escaping and avoidance behaviors.

Attentive Related to positioning of ears and head towards a threatening stimulus in the corral, considering the time presenting such behavior.

Positively Related to feed or water intake, considering occupied the time presenting these behaviors.

Curious Related to the time spent smelling or touching (with its muzzle) objects or corral structures.

Irritable Related to vigorous movements with the forelimbs (pawing), being combined or not with, tail whipping, blowing, and mooing.

Apathetic Related to the degree of liveliness expressed by the animals.

Comfortable Related to the degree of disturbance and annoyance during handling procedures.

Aggressive Related to aggressive behavior, occurrence of threat attacks to a subject (human or animal).

Sociable Related to the time spent on social interaction, on special affiliative behaviors (licking or grooming other animal's body).

Indifferent Related to the level of attention and reactions toward the facilities and handling procedures.
Animal does not show any escape or avoidance behavior nor muscle tremor.

Animal shows low frequencies and intensities of ears, tail, head, and limbs movements. No audible breathing.

Animal displays escape or avoidance behaviors most of the observation time.

Animal does not show any alert or vigilance behavior towards any potentially threatening stimulus, ears relaxed.

Animal does not display feed and water intake.

Animal does not smell or touch any structure in the corral.

Animal does not present any of the following behaviors: pawing, tail whipping, blowing, and mooing.

Animal alive, presenting reactions towards handling procedures and other stimulus.

Animal presents clear signs of disturbance during the handling procedures (high flight distance, audible breathing, tail flapping, and mooing).

Animal does not display aggressive behaviors of threat or attack any subject.

Animal does not present any positive social behavior toward other individuals.

Animal presents extreme attention or reactions to the corral environment and to handling facilities.
Animal does not present any evidence of muscular tension nor movements of ears, tail, and head.

Animal presents high flight distance toward humans and muscle tremor.

Animal presents frequent and vigorous movements of ears, tail, head and limbs, and audible breathing.

Animal does not display escape or avoidance behavior.

The animal stands with the head and ears directed to a potentially threatening stimulus most of the observation time.

Animal presents either one or both of these behaviors (water and feed intake)

Animal spends most of the observational time smelling or touching objects or corral structures.

Animal presents most or all of the following behaviors: pawing, tail whipping, blowing, or mooing, during most of the observation time.

Animal shows clear signs of weakness (lack of movements and head down), does not react to handling procedures.

Animal does not show signs of disturbance during handling procedures (low flight distance, no audible breathing, tail relaxed, and no vocalization).

Animal threatens or attacks any individual (human or another animal).

Animal presents positive physical contacts with another animal, such as licking or grooming its body.

Animal does not present any reaction, no signs of attention to corral environment or to handling procedures. 
variance $=1$ ). The coefficients of the linear functions defining the factors are used to interpret their meaning, using the sign and relative size of the coefficients as an indication of the weight to be placed upon each variable (loadings).

Many animals obtained a score of 0 for some adjectives, which were consequently excluded from the factor analyses. These were 'positively occupied', 'curious', 'irritable', 'apathetic', 'aggressive', 'sociable', and 'indifferent'. Three factor analyses (one for each farm) were then performed using the seven remaining adjectives: 'active', 'relaxed', 'fearful', 'agitated', 'calm', 'attentive', and 'comfortable'. The score obtained by each animal on the first factor (without any additional calculation) was used as a qualitative temperament index (QTI).

A linear mixed model using the REML method was fitted to assess the evolution of temperament over time for cattle kept under RSM, by using PROC MIXED in SAS (Statistical Analysis System, version 9.2) with a repeated statement. The statistical model included QTI as the dependent variable, and the fixed effects were farm (A, B, and C), evaluation (EV1 and EV2 at Farm A; EV1 to EV3 at Farm B; and EV1 to EV4 at Farm C), farmevaluation interaction, and lot within farm. The random effect of animal was considered a repeated measure within evaluation. We used an Unstructured (UN) residual variance and covariance, according to the Bayesian Information Criterion (BIC). Mean comparisons were performed using Tukey's test.

\section{Results}

The first factor obtained explained 53.37\%, 45.38\%, and $45.52 \%$ of the variability in the data sets of Farms A, $\mathrm{B}$, and $\mathrm{C}$, respectively (Table 3 ), while the second factor explained only a small proportion of the variation in the data sets $(15.03,15.64$, and $15.60 \%$ for Farms A, B, and C, respectively).

The first factor showed the highest negative contributions for the adjectives 'comfortable', 'relaxed', and 'calm' and the highest positive contribution for the adjective 'fearful' in all three farms assessed. Only for Farm A, the adjective 'agitated' also had a positive contribution to the first factor (Table 3). In general, the first factor was considered a qualitative temperament index (QTI), ranging from 'relaxed'/“calm'/'comfortable' (low QTI) to 'fearful'/'agitated' (high QTI), with the best temperament expressed by relaxed, calm, and comfortable animals during handling and the worst temperament by fearful and agitated animals.
We observed a significant interaction between farm and evaluation on QTI score $\left(\mathrm{F}_{3,6044}=22.46, \mathrm{P}<0.01\right)$. For Farms A and B, QTI decreased significantly at each subsequent evaluation $(\mathrm{P}<0.01)$, while for Farm $\mathrm{C}$, QTI did not differ significantly from the first to the second evaluation $(\mathrm{P}>0.05)$, but presented a significant reduction from the second assessment onwards (Table 4). For Farm A, QTI ranged from -1.74 (best temperament) to 4.08 (worst temperament). As seen in Figure 1 (Farm A), the animals in the second evaluation were more 'relaxed', 'calm', and 'comfortable' and less 'fearful' and 'agitated' when compared with the first evaluation. On Farm B, QTI ranged from -5.70 (best temperament) to 6.61 (worst temperament), and in the first evaluation of that farm, the animals received higher scores for the adjectives 'fearful' and 'agitated' and lower scores for 'relaxed', 'calm', and 'comfortable' relative to subsequent evaluations (Figure 1, Farm B). Finally, on Farm C, QTI ranged from -1.70 (best temperament) to 7.78 (worst temperament), and cattle received higher scores for the adjectives 'fearful' and 'agitated' and lower scores for 'relaxed', 'calm', and 'comfortable' on the first evaluation relative to the second, third, and fourth assessments (Figure 1, Farm C).

Table 3 - Factor analysis of observer rating to assess the temperament of beef cattle kept on rotational stocking method over time

\begin{tabular}{lccc}
\hline Adjective & Farm A & Farm B & Farm C \\
\hline Active & 0.440861 & 0.487785 & 0.388288 \\
Relaxed & $-0.904166^{*}$ & $-0.899773^{*}$ & $-0.932886^{*}$ \\
Fearful & $0.778558^{*}$ & $0.719008^{*}$ & $0.571729^{*}$ \\
Agitated & $0.791408^{*}$ & 0.570348 & 0.421023 \\
Calm & $-0.885715^{*}$ & $-0.840910^{*}$ & $-0.909818^{*}$ \\
Attentive & 0.112976 & 0.112907 & 0.136921 \\
Comfortable & $-0.829900^{*}$ & $-0.752981^{*}$ & $-0.900166^{*}$ \\
Eigenvalues & 3.736051 & 3.177102 & 3.187064 \\
\% Total variance & 53.37215 & 45.38718 & 45.52948 \\
\hline
\end{tabular}

Values were obtained by factor analysis with principal components method, for each farm of the study.

* Loadings representing the adjectives with the most positive and negative contributions to the composition of the Qualitative temperament index.

Table 4 - Temperament evolution of beef cattle kept under rotational stocking method based on the qualitative temperament index (QTI)

\begin{tabular}{lcccc}
\hline \multirow{2}{*}{ Farm } & \multicolumn{4}{c}{ Evaluation (EV) } \\
\cline { 2 - 5 } & EV1 & EV2 & EV3 & EV4 \\
\hline Farm A & $0.28 \pm 0.04 \mathrm{aAB}$ & $-0.28 \pm 0.04 \mathrm{bC}$ & - & - \\
Farm B & $0.23 \pm 0.04 \mathrm{aB}$ & $0.07 \pm 0.03 \mathrm{bB}$ & $-0.29 \pm 0.03 \mathrm{cA}$ & - \\
Farm C & $0.39 \pm 0.04 \mathrm{aA}$ & $0.39 \pm 0.03 \mathrm{aA}$ & $-0.26 \pm 0.03 \mathrm{bA}$ & $-0.56 \pm 0.03 \mathrm{c}$ \\
\hline
\end{tabular}

Data are expressed as means ( \pm standard error) of QTI.

a-d - means followed by the same letters in the rows are not statistically different ( $\mathrm{P}>0.05)$ by Tukey's test.

A-C - means followed by the same letters in the columns are not statistically different. 


\section{Discussion}

Although little time was available to observe each individual animal during the temperament assessment, and while the behavioral expression of only half of the adjectives were observed ('active', 'relaxed', 'fearful', 'agitated', 'calm', 'attentive', and 'comfortable'), the observer rating method was an adequate way to characterize cattle temperament during the handling routine in the corral. We thus conclude that this qualitative method successfully captures individual and temporal variations in cattle behavior.

The adjectives that contributed the most to the first factor were 'relaxed', 'calm', and 'comfortable' (reflecting better temperament) and 'fearful' and 'agitated' (reflecting worse temperament). Similar results were reported by
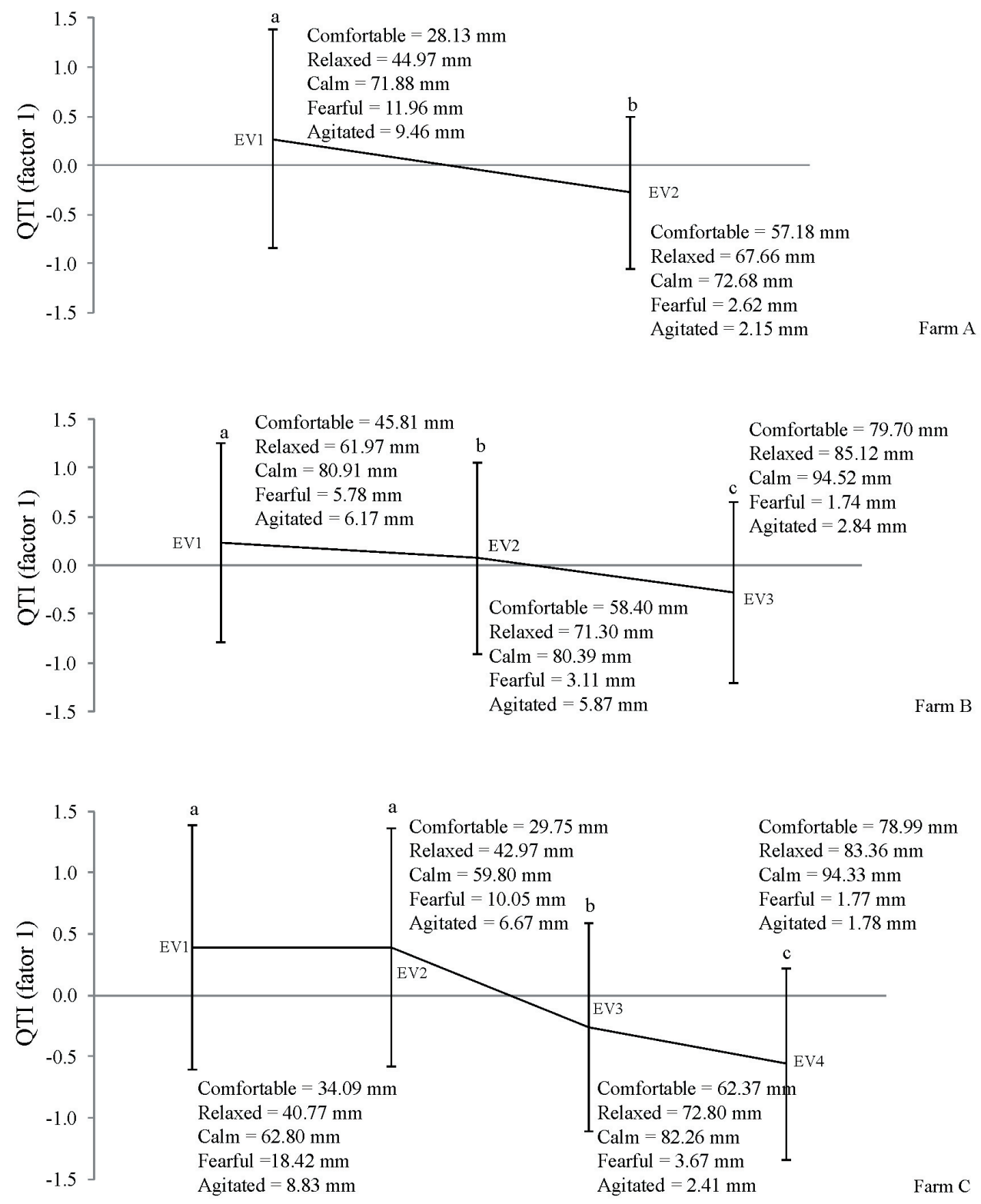

The means $(\mathrm{mm})$ for each adjective used in the observers rating method with highest positives and negatives contributions to the composition of QTI to Farms A, B, and C are presented.

Means with the same letters across on the standard deviations bars did not differ statistically (Tukey's test; P $>0.05$ ).

Figure 1 - Mean and standard deviations of the qualitative temperament index (QTI) of cattle kept under rotational stocking method over time. 
Sant'Anna and Paranhos da Costa (2013), who used a temperament index (TI) that also ranged from the most excitable (highest negative loadings for 'agitated' and 'active') to the calmest temperaments (highest positive loadings for 'calm' and 'relaxed'). It is worth noting that those authors did not include the adjective 'comfortable' in their study.

Using QBA to measure dairy cattle welfare, Andreasen et al. (2013) also obtained the highest negative contribution for the adjectives 'calm'/'relaxed', and the highest positive loadings for 'uneasy'/'frustrated', thus also reflecting a continuum from positive to negative behavioral expressions in their animals. In a study that used the QBA to determine the emotional states and welfare of other farm species with a first dimension comparable to ours, adjectives ranged from 'calm' to 'agitated' in dairy buffaloes (Napolitano et al., 2012), and from 'calm'/'content'/'relaxed' to 'agitated'/'angry'/'annoyed' in endurance horses (Fleming et al., 2013). All of these results demonstrate that the adjectives used in the observer ratings were well spaced apart, and reflected a continuum between the desirable and undesirable behaviors of animals expressed within a principal dimension.

We observed that the temperament (represented here by QTI values) of cattle kept under RSM improved over time, as reflected by a reduction of 'fearful' and 'agitated' expressions, combined with an increase in 'relaxed', 'calm', and 'comfortable' expressions. This improvement in temperament over time was expected, since the animals underwent frequent interactions with the stockpersons. Indeed, the RSM involves driving cattle from a grazed paddock to a new one (with better grass) in short time intervals; additionally, cattle were handled in the corral on a monthly basis, and always in a non-aversive way. Under such conditions, the handling procedures were probably perceived by the animals as positive or neutral, which would have led to learning (e.g., operant conditioning and habituation to humans and handling facilities). An improvement in cattle temperament over time has also been reported by several authors (Andrade et al., 2001; Petherick et al., 2002; Fina et al., 2006; Barbosa Silveira et al., 2008; Titto et al., 2010) who used the flight speed or crush score tests over successive handlings to assess cattle kept in feedlots or in extensive systems. One report also measured the habituation to handling of the animals (Barbosa Silveira et al., 2008).

The QBA method has also been used to evaluate behavioral expression longitudinally in cattle (Stockman et al., 2011) and sheep (Wickham et al., 2012). In both studies, the animals were scored before and after transportation, and the QBA distinguished between animals that were naïve to transport from those which were habituated to it. For both cattle and sheep, the naïve animals showed higher ratings for the 'agitated'/'alert'/'anxious' adjectives than the habituated animals, which presented higher ratings for 'calm'/'comfortable'. A similar trend was observed in our study; namely, cattle were more 'calm'/'comfortable' as the time in RSM progressed and animals were likely more habituated to handling. By contrast, in Fleming et al. (2013), QBA did not capture individual response differences over time in endurance horses, leading the authors to suggest that more research be conducted with QBA and animal temperament.

Besides detecting cattle temperament changes over time, the observer rating method used in the present study proved to be highly sensitive, as it measured both positive and negative aspects of animal temperament. Therefore, it distinguished between 'calm'/'relaxed'/'comfortable' animals and 'fearful'/'agitated' ones. Thus, the current observer rating method may be a viable alternative to conventional methods of cattle temperament evaluation such as flight speed, crush scores, and temperament score in a corral pen (Burrow, 1997; MacKay et al., 2013; Haskell et al., 2014), which only discriminate between animals with or without undesirable temperaments (e.g., highly fearful, aggressive, or reactive), while ignoring positive expressions.

In summary, we believe that by including positive and negative behavioral expressions on a single scale, the observer rating method promotes a broader view of cattle temperament over time. Thus, further research should be conducted to evaluate the inter-observer reliability for the two types of qualitative approaches (with and without predefined adjectives) to confirm whether the descriptions for each adjective do in fact minimize the undesirable methodological limitations and thus increase reliability.

\section{Conclusions}

The observer rating method proposed here, which uses behaviorally defined adjectives, is applicable as a cattle temperament indicator under field conditions. The method could even be applied in a fast handling condition at the corral, as it captures different aspects of cattle temperament. Furthermore, it identifies slight variations in the body language of cattle reared in the rotational stocking method, thus adequately detecting their temperament changes over time. 


\section{Acknowledgments}

We would like to thank the owners and staff of Marupiara, Santa Maria, and São Luiz farms for their help and kind reception in their houses. We are also grateful to Projeto Pecuária Verde Project for the financial support. The study was part of the Master's thesis of the lead author of the manuscript in the Graduate Program in Animal Science at São Paulo State University (UNESP), Jaboticabal Campus, Brazil.

\section{References}

Allen, V. G.; Batello, C.; Berretta, E. J.; Hodgson, J.; Kothmann, M.; Li, X.; Mcivor, J.; Milne, J.; Morris, C. and Peeters, A. and Sanderson, M. 2011. An international terminology for grazing lands and grazing animals. Grass and Forage Science 66:2-28.

Allport, G. W. and Odbert, H. S. 1936. Trait-names: A psycho-lexical study. Psychological Monographsl 47:1-171.

Andrade, O.; Orihuela, A.; Solano, J. and Galina, C. S. 2001. Some effects of repeated handling and the use of a mask on stress responses in zebu cattle during restraint. Applied Animal Behaviour Science 71:175-181.

Andreasen, S. N.; Wemelsfelder, F.; Sandøe, P. and Forkman, B. 2013. The correlation of Qualitative Behavior Assessments with Welfare Quality ${ }^{\circledR}$ protocol outcomes in on-farm welfare assessment of dairy cattle. Applied Animal Behaviour Science 143:9-17.

Barbosa Silveira, I. D.; Fischer, V. and Wiegand, M. M. 2008. Temperamento em bovinos de corte: métodos de medida em diferentes sistemas produtivos. Archivos de Zootecnia 57:321-332.

Bokkers, E. A. M.; de Vries, M.; Antonissen, I. C. M. A. and de Boer, I. J. M. 2012. Inter-and intra-observer reliability of experienced and inexperienced observers for the qualitative behaviour assessment in dairy cattle. Animal Welfare 21:307-318.

Burrow, H. M. 1997. Measurements of temperament and their relationships with performance traits of beef cattle. Animal Breeding Abstracts 65:477-495.

Byrne, G. and Suomi, S. J. 2002. Cortisol reactivity and its relation to homecage behavior and personality ratings in tufted capuchin (Cebus apella) juveniles from birth to six years of age. Psychoneuroendocrinology 27:139-154.

Carlstead, K.; Mellen, J. and Kleiman, D. G. 1999. Black rhinoceros (Diceros bicornis) in US zoos: I. Individual behavior profiles and their relationship to breeding success. Zoo Biology 18:17-34

Deary, I. J. A. 1996. A (latent) Big Five personality model in 1915? A reanalysis of Webb's data. Journal of Personality and Social Psychology 71:992.

Fina, M.; Casellas, J.; Manteca, X. and Piedrafita, J. 2006. Analysis of temperament development during the fattening period in the semi-feral bovine calves of the Alberes Massif. Animal Research 55:389-395.

Fleming, P. A.; Paisley, C. L.; Barnes, A. L. and Wemelsfelder, F. 2013. Application of Qualitative Behavioural Assessment to horses during an endurance ride. Applied Animal Behaviour Science 144:80-88.

Gold, K. C. and Maple, T. L. 1994. Personality assessment in the gorilla and its utility as a management tool. Zoo Biology 13:509-522.

Grand, A. P.; Kuhar, C. W.; Leighty, K. A.; Bettinger, T. L. and Laudenslager, M. L. 2012. Using personality ratings and cortisol to characterize individual differences in African Elephants
(Loxodonta africana). Applied Animal Behaviour Science 142:69-75.

Haskell, M. J.; Simm, G. and Turner, S. P. 2014. Genetic selection for temperament traits in dairy and beef cattle. Frontiers in genetics $5: 1-18$.

Jeffers, J. N. R. 1978. An introduction to systems analysis: with Ecological applications. Edward Arnold Publisher, London.

Kuhar, C. W.; Stoinski, T. S.; Lukas, K. E. and Maple, T. L. 2006. Gorilla behavior index revisited: age, housing and behavior. Applied Animal Behaviour Science 96:315-326.

Lerman, D. C.; Tetreault, A.; Hovanetz, A.; Bellaci, E.; Miller, J.; Karp, H.; Mahmood, A.; Strobel, M.; Mullen, S.; Keyl, A. and Toupard. A. 2010. Applying signal-detection theory to the study of observer accuracy and bias in behavioural assessment. Journal of Applied Behaviour Analysis 43:195-213.

MacKay, J. R. D.; Turner, S. P.; Hyslop, J.; Deag, J. M. and Haskell, M. J. 2013. Short-term temperament tests in beef cattle relate to long-term measures of behavior recorded in the home pen. Journal of animal science 91:4917-4924.

Martin, J. E. 2005. The influence of rearing on personality ratings of captive chimpanzees (Pan troglodytes). Applied Animal Behaviour Science 90:167-181.

Martin, P. and Bateson, P. 2007. Measuring behaviour: An introductory guide. 3th ed. Cambridge University Press, Cambridge.

Minero, M.; Dalla Costa, E.; Dai, F.; Murray, L. A. M.; Canali, E. and Wemelsfelder, F. 2015. Use of qualitative behaviour assessment as an indicator of welfare in donkeys. Applied Animal Behaviour Science 174:147-153.

Napolitano, F.; De Rosa, G.; Grasso, F. and Wemelsfelder, F. 2012. Qualitative behaviour assessment of dairy buffaloes (Bubalus bubalis). Applied Animal Behaviour Science 141:91-100.

Petherick, J. C.; Holroyd, R. G.; Doogan, V. J. and Venus, B. K. 2002. Productivity, carcass and meat quality of lot-fed Bos indicus cross steers grouped according to temperament. Australian Journal of Experimental Agriculture 42:389-398.

Phythian, C.; Michalopoulou, E.; Duncan, J. and Wemelsfelder, F. 2013. Inter-observer reliability of qualitative behavioural assessments of sheep. Applied Animal Behaviour Science 144:73-79.

Rousing, T. and Wemelsfelder, F. 2006. Qualitative assessment of social behaviour of dairy cows housed in loose housing systems. Applied Animal Behaviour Science 101:40-53.

Sant'Anna, A. C. and Paranhos da Costa, M. J. R. 2013. Validity and feasibility of qualitative behavior assessment for the evaluation of Nellore cattle temperament. Livestock Science 157:254-262.

Stevenson-Hinde, J. and Zunz, M. 1978. Subjective assessment of individual rhesus monkeys. Primates 19:473-482.

Stockman, C. A.; Collins, T.; Barnes, A. L.; Miller, D.; Wickham, S. L.; Beatty, D. T.; Blache, D.; Wemelsfelder, F. and Fleming, P. A. 2011. Qualitative behavioural assessment and quantitative physiological measurement of cattle naïve and habituated to road transport. Animal Production Science, 51:240-249.

Stockman, C. A.; McGilchrist, P.; Collins, T.; Barnes, A. L.; Miller, D.; Wickham, S. L.; Greenwood, P. L.; Cafe, L. M.; Blache, D.; Wemelsfelder, F. and Fleming, P. A. 2012. Qualitative Behavioural Assessment of Angus steers during pre-slaughter handling and relationship with temperament and physiological responses. Applied Animal Behaviour Science 142:125-133.

Titto, E. A. L.; Titto, C. G.; Gatto, E. G.; Silva, N. C. M.; Mourão, G. B.; Nogueira Filho, J. C. M. and Pereira, A. M. F. 2010. Reactivity of Nelore steers in two feedlot housing systems and its relationship with plasmatic cortisol. Livestock Science 129:146-150.

Tuyttens, F. A. M.; de Graaf, S.; Heerkens, J. L.; Jacobs, L.; Nalon, E.; Ott, S.; Stadig, L.; Van Laer, E. and Ampe, B. 2014. Observer bias 
in animal behaviour research: can we believe what we score, if we score what we believe?. Animal Behaviour 90:273-280.

Weiss, A.; King, J. E. and Hopkins, W. D. 2007. A cross-setting study of chimpanzee (Pan troglodytes) personality structure and development: zoological parks and Yerkes National Primate Research Center. American Journal of Primatology 69:1264-1277.

Wemelsfelder, F.; Hunter, E. A.; Mendl, M. T. and Lawrence, A. B. 2000. The spontaneous qualitative assessment of behavioural expressions in pigs: first explorations of a novel methodology for integrative animal welfare measurement. Applied Animal Behaviour Science 67:193-215.

Wielebnowski, N. C. 1999. Behavioral differences as predictors of breeding status in captive cheetahs. Zoo Biology 18:335-349.

Wickham, S. L.; Collins, T.; Barnes, A. L.; Miller, D. W.; Beatty, D. T.; Stockman, C.; Blache, F.; Wemelsfelder, F. and Fleming, P. A. 2012. Qualitative behavioral assessment of transportnaïve and transport-habituated sheep. Journal of Animal Science 90:4523-4535. 